\title{
Gurs 1940. Die Deportation und Ermordung von südwestdeutschen Jüdinnen und Juden
}

Eine Ausstellung in der WLB vom 11. Mai bis 18. Juli 2021

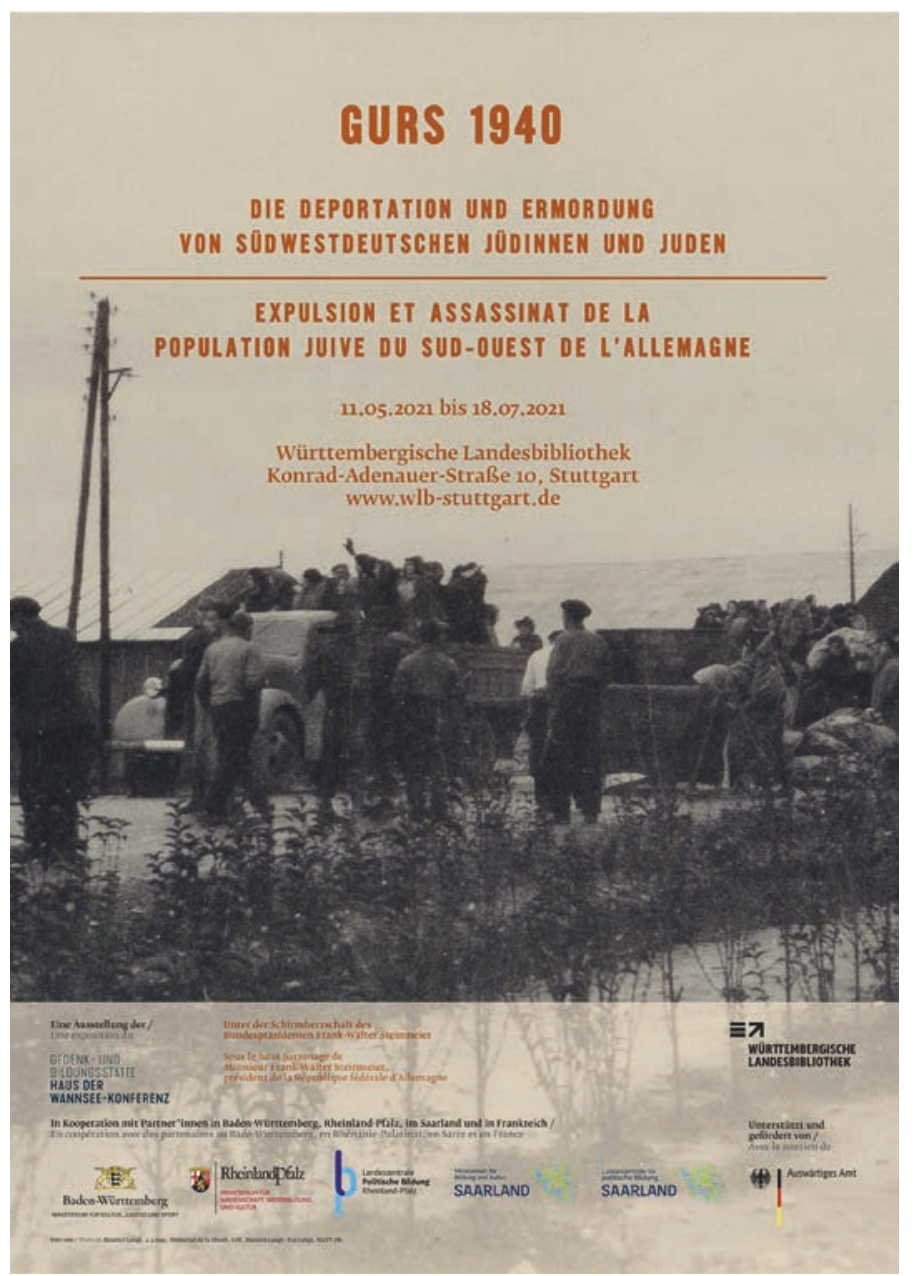

Abb. 1: Plakat zur Ausstellung

Am 22. und 23. Oktober 1940 wurden Tausende Jüdinnen und Juden aus Baden und der Saarpfalz in den unbesetzten Teil Frankreichs deportiert. Offizielle Quellen sprechen von 6.504 Menschen. Die Zahl lag sicherlich höher. Dies war eine der ersten organisierten Verschleppungen von jüdischen Deutschen aus ihrer Heimat, initiiert von den regionalen nationalsozialistischen Verantwortlichen, den Gauleitern. Erst ein Jahr später begannen die systematischen Deportationen aus dem gesamten Deutschen Reich in den Osten. Die französischen Behörden leiteten die Transporte in das Lager Gurs, am Fuße der Pyrenäen, im Herzen des heutigen Departements Pyrénées-Atlantiques. Einigen der Deportierten gelang von dort die Flucht, mehr als tausend starben in den kommenden Jahren aufgrund der katastrophalen Lebensbedingungen.

Zwischen 1942 und 1944 organisierten SS und Polizei die Deportation der Internierten nach Auschwitz-Birkenau und Sobibor, wo fast alle ermordet wurden. An diese Verbrechen und ihre Nachgeschichte erinnert diese Ausstellung. Auf 14 Stellwänden mit 28 Tafeln bettet sie regionale Geschichte in deutsche, französische und europäische Abläufe ein und nimmt Betroffene, aber auch Täter, Umstehende und Nutznießende in Deutschland und Frankreich aus verschiedenen Perspektiven in den Blick. Sie erzählt, wie dieser Verbrechen gedacht wurde und wird.

Die Ausstellung steht unter der Schirmherrschaft des Bundespräsidenten Frank-Walter Steinmeier. Sie ist in der Gedenk- und Bildungsstätte Haus der Wannsee-Konferenz in Kooperation mit vielen

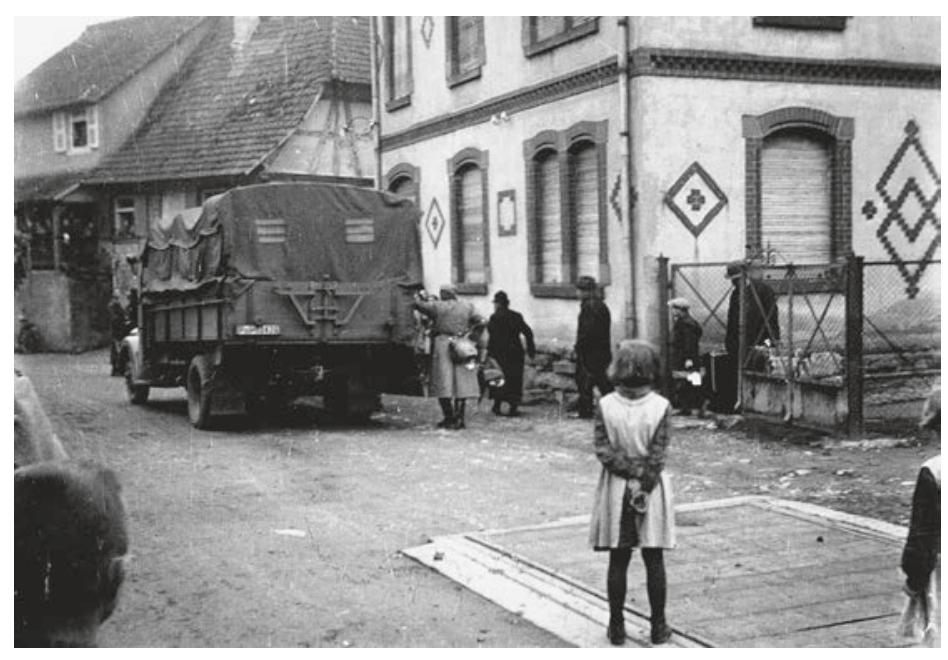

Abb. 2: Kippenheim, 22. Oktober 1940. Bildunterschrift von Kurt Salomon Maier: "Wir werden abgeholt".

(Foto: Wilhelm Fischer, 22.10.1940, Förderverein Ehemalige Synagoge Kippenheim)

Partnern aus Baden-Württemberg, Rheinland-Pfalz, dem Saarland und Frankreich sowie dem Auswärtigen Amt entstanden. Die Ausstellung wird 


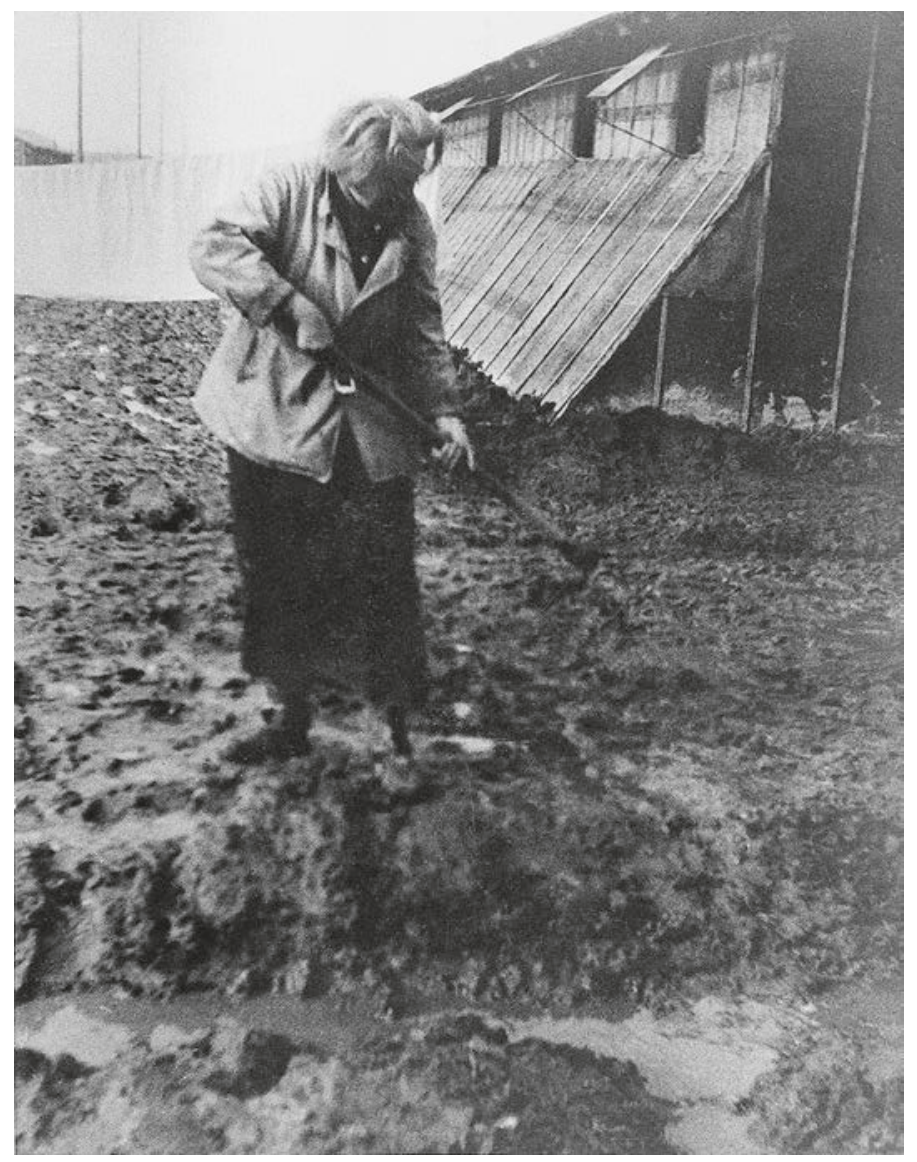

Abb. 3: Das Lager Gurs war unbefestigt, bei Regen weichte der Boden völlig auf. Mit einer Feldhacke versucht hier eine Frau, einen Abwassergraben zu vertiefen.

(Foto: Unbekannter Fotografen/ unbekannte Fotografin, ca. 1942, Staatsarchiv Stuttgart, EA 99/001 Bü 304, Nr. 14 Bild 1)

an verschiedenen Orten in Südwestdeutschland gezeigt. Die Stuttgarter Ausführung wurde vom Ministerium für Kultus, Jugend und Sport BadenWürttemberg realisiert.

Zur Ausstellung ist eine Begleitbroschüre erschienen, die in der WLB erhältlich ist. Weiterführende Informationen sowie eine gesamte Abbildung der Präsentation finden sich außerdem auf der Website: https://www.gurs1940.de
Im Vortragssaal der WLB, Konrad-Adenauer-Straße 10, finden folgende Begleitveranstaltungen statt:

\subsubsection{1, 18 Uhr}

Buchvorstellung mit Gespräch in der Vortragsreihe der Bibliothek für Zeitgeschichte im Rahmen des Festjahres 2021 - 1700 Jahre jüdisches Leben in Deutschland:

Levi Israel Ufferfilge (Berlin): Nicht ohne meine Kippa! Mein Alltag in Deutschland zwischen Klischees und Antisemitismus

\subsubsection{1, 18 Uhr}

"Antisemitismus und Lesen" Vortrag von Dr. Michael Blume, Beauftragter gegen Antisemitismus der Landesregierung Baden-Württemberg

\subsubsection{1, $18 \mathrm{Uhr}$}

"Todesfuge. Biographie eines Gedichts." Dr. Thomas Sparr (Berlin) im Gespräch mit Dr. Barbara Wiedemann (Tübingen) 